\title{
Simvastatin promotes alveolar epithelial cell proliferation and attenuates cigarette smoke-induced emphysema in rats
}

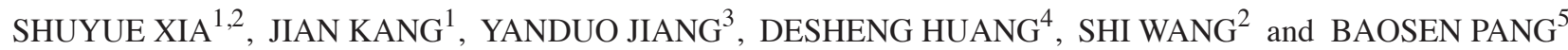 \\ ${ }^{1}$ Institute of Respiratory Disease, The First Affiliated Hospital of China Medical University, Shenyang, Liaoning 110001; \\ ${ }^{2}$ Department of Pulmonary Medicine, Central Hospital affiliated to Shenyang Medical College, Shenyang, Liaoning 110024; \\ ${ }^{3}$ Department of Pathology, 202nd Hospital of PLA, Shenyang, Liaoning 110812; ${ }^{4}$ Department of Mathematics, \\ College of Basic Medical Sciences, China Medical University, Shenyang, Liaoning 110013; \\ ${ }^{5}$ Beijing Institute of Respiratory Medicine, Beijing Chaoyang Hospital affiliated to Capital Medical University, \\ Beijing 100069, P.R. China
}

Received August 26, 2014; Accepted March 23, 2015

DOI: $10.3892 / \mathrm{mmr} .2015 .4172$

\begin{abstract}
Current treatments for chronic obstructive pulmonary disease (COPD) cannot reverse the pathological process of the disease, therefore, the development of novel agents and strategies for COPD treatment is required. The aim of the present study was to investigate the potential therapeutic value of simvastatin ( $\mathrm{SmSt})$ in cigarette smoke-induced emphysema in rats. A total of 24 male and female Wistar rats were randomly divided into four groups. The levels of vascular endothelial growth factor (VEGF) in the lung tissues and bronchoalveolar lavage (BAL) fluid of each group were measured using an enzyme-linked immunoassay. The mRNA expression of VEGF was assessed using reverse transcription-quantitative polymerase chain reaction. The protein expression levels of VEGF and proliferating cell nuclear antigen (PCNA) were determined using immunohistochemical assays. Histological scoring revealed that simvastatin reduced the total inflammatory scores significantly more in the simvastatin-treated smoke-exposed group, compared with the smoke exposed (Sm) group. Significant differences in the average inter-alveolar septal wall distance and mean alveolar numbers were also observed between the SmSt and Sm groups. The levels of VEGF in the BAL fluid and lung tissue homogenates of the SmSt group were similar to those in the simvostatin-only (St) and control (CtL) groups, and significantly higher compared with those in the Sm group. The expression of VEGF in the alveolar and bronchial epithelial cells of the SmSt group was similar to that in the CtL group, and significantly higher compared with
\end{abstract}

Correspondence to: Professor Jian Kang, Institute of Respiratory Disease, The First Affiliated Hospital of China Medical University, 155 Nan-Jing-Bei Street, Heping, Shenyang, Liaoning 110001, P.R. China

E-mail: jiangkangcn@163.com

Key words: emphysema, lung epithelium, vascular endothelial growth factor, statins that of the Sm group. The percentage of PCNA-positive alveolar epithelial cells was significantly higher in the SmSt group compared with the Sm and CtL groups. Simvastatin exerted a significant impact on the expression of VEGF and attenuated cigarette smoke-induced emphysema in rats. Therefore simvastatin may have beneficial effects in patients with COPD.

\section{Introduction}

Chronic obstructive pulmonary disease (COPD) is a term used for diseases, which cause lung impairment and breathlessness. The World Health Organization indicated that COPD was the fifth leading cause of mortality in 2002 and was predicted to become the third leading cause of mortality in 2030 (1). A previous large population, spirometry-based epidemiological investigation reported that, in China, the prevalence of COPD in adults $>40$ years was $8.2 \%$ (12.4\% in men; $5.1 \%$ in women) (2). Therefore, COPD is likely to become an important health care problem worldwide.

COPD is associated with characteristic pathological changes in the small airways, including obstructive bronchiolitis, and the destruction of lung parenchyma, including emphysema. Current therapies for COPD, including inhaled corticosteroids and long-acting agonists, improve the pulmonary function and quality of life in patients with COPD, however, they cannot reverse the pathological process of COPD. Therefore, the identification of novel therapies for COPD is an area of intense investigation (3-5).

Liebow (6) demonstrated that the alveolar septa in patients with COPD were thin and almost avascular, suggesting that a reduction of the small capillary blood vessels may lead to subsequent alveolar septal loss. Vascular endothelial growth factor (VEGF) signaling is important for maintaining lung structure. Kasahara et al (7) demonstrated that the expression of VEGF and its receptor in the lung tissues of patients with emphysema were significantly lower than normal. Therefore, a decrease in VEGF or disruption to the VEGF signaling pathway may affect the pathogenesis of emphysema. However, the effect of levels of VEGF on airway epithelial cells, which are in direct contact with the environment, remains to be fully 
elucidated (8). It has been suggested that statins may modulate VEGF synthesis, and the pleiotropic effects of statins with regard to their use in COPD treatment has received more attention $(9,10)$.

Statins are potent inhibitors of 3-hydroxy-3-methylglutaryl coenzyme A reductase, and exhibit pleiotropic pharmacological effects (11). In addition to a cholesterol-lowering effect, they exhibit anti-inflammatory, antioxidant and immunomodulatory properties, and improve endothelial function in chronic inflammatory lung disease (10). A number of these statin pleiotropic effects are mediated by the inhibition of isoprenylation of small guanosine-5'-triphosphate-binding signaling molecules, including the Rho, Ras and Rac proteins (12). The anti-inflammatory effects include the suppression of the release of proinflammatory cytokines, chemokines, adhesion molecules and matrix metalloproteinases by inflammatory cells. Statins increase the secretion of VEGF and the expression and activity of endothelial nitric oxide synthase, which improves endothelial cell function and promotes angiogenesis (13). There is evidence that statins exert cell type-dependent effects on endothelial cell angiogenic activity and on VEGF synthesis (14). It has been reported that simvastatin may induce apoptosis in hyper-proliferative pulmonary vascular lesions (15) and may inhibit the development of colon cancer via the induction of apoptosis and suppression of angiogenesis (16).

Cigarette smoking is the most important and common risk factor for COPD, however, the underlying pathological mechanisms remain to be elucidated $(17,18)$. Therefore, the present study performed assays in order to investigate the effects of statins on the expression of VEGF, based on the morphometric parameters in cigarette smoke-induced lung emphysema, using a rat model. A number of cell functions, including differentiation, proliferation, and apoptosis can be affected by simvastatin (19). The effect of statins on the expression of proliferating cell nuclear antigen (PCNA) was also investigated.

\section{Materials and methods}

Reagents and materials. Male $(\mathrm{n}=12)$ and female $(\mathrm{n}=12)$ Wistar rats (12-week-old; 190-220 g; Chinese Academy of Medical Sciences, Beijing, China) were included in the present study, which was approved by the Division of Laboratory Animal Medicine at the China Medical University (Shenyang, China; certificate no. SVXK, Liao, 2003-0009). The animals were housed in Plexiglas cages (Guxiu, Suzhou, China), with males and females housed separately, under a 12:12 h light-darkness cycle in temperature and humidity controlled rooms. Standard laboratory food and water were provided ad libitum. The present study was performed in accordance with the recommendations in the Guide for the Care and Use of Laboratory Animals of the National Institutes of Health (20). The animal use protocol was reviewed and approved by the Institutional Animal Care and Use Committee of China Medical University.

Treatment groups. The rats were numbered in ascending order of weight and divided into four groups. The four groups of rats ( $n=6$ in each group) were randomly assigned to the following groups: Control (CtL); smoke-exposed only (Sm); simvastatin-only (St); and smoke + simvastatin $(\mathrm{SmSt})$. The $\mathrm{Sm}$ and SmSt groups were exposed to the smoke from 16 commercial Da-Sheng-Chan cigarettes (Hongta Liaoning Tobacco Co., Ltd., Shenyang Cigarette Factory, Liaoning, China) for $1 \mathrm{~h}$ each day for 16 weeks. Simvastatin (Merck Sharp \& Dohme, Ltd., Hoddeston, UK) was administered orally to the SmSt and St groups at a dose of $5 \mathrm{mg} / \mathrm{kg}(21,22)$, once daily for the 16 week period.

Morphometric evaluation of the lungs. Following 16 weeks of treatment, the rats were anesthetized using pentobarbital sodium $(50 \mathrm{mg} / \mathrm{kg}$, intraperitoneally; Sigma-Aldrich, St. Louis, MO, USA) and sacrificed by cervical vertebra dislocation. The bilateral lung were excised from the chest. The right lung tissues were fixed in 10\% neutral buffered formalin (Sigma-Aldrich), embedded in paraffin blocks (Leica Microsytems $\mathrm{GmbH}$, Wetzlar, Germany), cut into $4-\mu \mathrm{m}$ serial sections. The right lung was used for histological analyses. The inflammation score of the small airways $(300-1,100-\mu \mathrm{m})$ consisted of the following: Epithelial loss, erosion and ulcer formation; goblet cell hyperplasia and hypertrophy; ciliated epithelium lodging; inflammatory cell infiltration; lymph follicle formation; bronchial stenosis; airway smooth-muscle cell proliferation disorder; connective tissue proliferation; squamous metaplasia; wall congestion, edema; and wall pigmentation. Hematoxylin-and-eosin (HE; Leica Microsystems GmbH) was used to stain hilar areas of the lung tissue, in order to assess the small-airway pathology score, using two independent investigators, in a blinded-manner [Three small-airway sections, composite score 100/3, total score 100/33 (3 x 11)] (23). The tissues were viewed under a light microscope (BX51, Olympus Corporation, Tokyo, Japan).

Standard morphometric measurements were used to determine emphysematous changes. A total of 10 randomly selected HE-stained hilar areas from each sample (magnification, low power field) were used to analyze changes in air space size, which was determined by the average interalveolar septal wall distance (mean linear intercept; MLI). The alveolar density was determined by the mean alveolar number (MAN) (24).

Measurements of VEGF and PCNA. Measurements of VEGF in the bronchoalveolar lavage fluid (BALF) were performed in order to investigate the effect of simvastatin. For preparation of BALF and measurement of VEGF in the BALF, each rats was anesthetized using $10 \%$ neutral buffered formalin (Sigma-Aldrich), the trachea were exposed and intubated and the left lung was washed three times using $2 \mathrm{ml}$ sterile saline, at $0^{\circ} \mathrm{C}$. BALF was collected using a $5 \mathrm{ml}$ syringe and placed on ice. Following centrifugation at $400 \mathrm{x} \mathrm{g}$ for $5 \mathrm{~min}$ at $4^{\circ} \mathrm{C}$, the VEGF concentration was measured in the supernatants using an enzyme-linked immunosorbent assay (ELISA; Santa Cruz Biotechnology Inc., Santa Cruz, CA, USA), according to the manufacturer's instructions.

To determine the levels of VEGF in the lungs in each group, the lung tissues were homogenized in phosphate-buffered saline (PBS; Wake Pure Chemical Industries, Osaka, Japan), and the supernatant was obtained by ultracentrifugation at $11,100 \mathrm{x} \mathrm{g}$ for $10 \mathrm{~min}$ at $4^{\circ} \mathrm{C}$. The level of VEGF in the supernatant was determined using a commercially available ELISA kit (Quantikine Mouse VEGF kit; R\&D Systems, Inc., 
Table I. Total inflammation scores and results of morphometric evaluation in the four study groups 16 weeks after treatment.

\begin{tabular}{lccr}
\hline Group & TIS & MLI $(\mu \mathrm{m})$ & MAN $\left(\mathrm{n} / \mathrm{nm}^{2}\right)$ \\
\hline CtL & $43.43 \pm 24.97$ & $58.72 \pm 5.98$ & $138.07 \pm 6.74$ \\
Sm & $84.85 \pm 48.96^{\mathrm{a}}$ & $79.31 \pm 25.31^{\mathrm{a}}$ & $84.56 \pm 31.83^{\mathrm{b}}$ \\
St & $47.78 \pm 31.24$ & $50.64 \pm 6.02$ & $128.42 \pm 33.55^{\mathrm{c}}$ \\
SmSt & $45.96 \pm 23.27^{\mathrm{b}}$ & $60.46 \pm 4.28^{\mathrm{b}}$ & $132.11 \pm 11.22^{\mathrm{c}}$ \\
F-statistic & 3.321 & 4.789 & 5.700 \\
P-value & $<0.05$ & $<0.05$ & $<0.01$ \\
\hline
\end{tabular}

Values are presented as the mean \pm standard deviation ( $\mathrm{n}=6$ in each group). ${ }^{\mathrm{a}} \mathrm{P}<0.05$, compared with the $\mathrm{CtL}$ group. ${ }^{\mathrm{b}} \mathrm{P}<0.05$ and ${ }^{\mathrm{c}} \mathrm{P}<0.01$, compared with the Sm group. TIS, total inflammation score; MLI, mean linear intercept; MAN, mean alveolar number. CtL, control; Sm, smoke exposed; St, simvastatin treated; SmSt, smoke exposed \pm simvastatin treated.

Minneapolis, MN, USA), according to the manufacturer's instructions.

Immunohistochemical staining and quantification. In order to perform immunohistochemical scoring analysis for VEGF and PCNA, hilar sections $(5-\mu \mathrm{m})$ were deparaffinized in xylene (Shenyang Chemical Reagent Plant, Shenyang, China) and rehydrated. Antigen retrieval was performed by heating the lung tissue in a microwave (MYE-1870MEG; Haier, Qingdao, China) in $10 \mathrm{mmol} / 1$ citric acid monohydrate for $5 \mathrm{~min}$ at $900 \mathrm{~W}$ and three times for $5 \mathrm{~min}$ at $600 \mathrm{~W}$. Endogenous peroxidase activity was inhibited by incubating the samples with $0.5 \%$ $\mathrm{H}_{2} \mathrm{O}_{2}$ for $10 \mathrm{~min}$. The slides were incubated overnight at $4^{\circ} \mathrm{C}$ in the appropriate dilutions of the primary antibodies (mouse anti-PCNA monoclonal antibody (1:100; cat. no. sc-25280; Santa Cruz Biotechnology, Inc.) and VEGF monoclonal antibody (1:100; cat. no. sc-7269; Santa Cruz Biotechnology, Inc.). The slides were incubated for $60 \mathrm{~min}$ at room temperature (20-22 $2^{\circ}$ ), rinsed for 2 min with PBS three times, and incubated in 3, 3'-diaminobenzidine. The slides were then evaluated using light microscopy (BX51; Olypmus Corporation).

The percentages of VEGF- and PCNA-positive small-airway and alveolar epithelial cells (AECs) were calculated. The staining was scored as follows: Expression of VEGF was localized in the cytoplasm, and the expression of PCNA was localized in the cell nucleus. The 500 cells were randomly selected in the bronchiolar epithelium, alveolar epithelium and vascular endothelial cells in each slide at 400x magnification. The number of cells expressing VEGF or PCNA were counted, respectively

The entire tissue samples were scored using the same magnification factor. The staining intensities of VEGF and PCNA in the SAECs, AECs and vascular endothelial cells (VECs were scored by independent investigators in a blinded-manner, in order to avoid observer bias.

Analysis of the expression of VEGF. Reverse transcription-quantitative polymerase chain reaction (RT-qPCR) was used to analyze the expression levels of VEGF by amplifying the coding parts of the VEGF gene. Total lung RNA was isolated using TRIzol reagent (Invitrogen Life Technologies), according to the manufacturer's instructions. RNA concentration was measured by absorption at $260 \mathrm{~nm}$ and the purity of the RNA was guaranteed based on a absorption ratio of $260 \mathrm{~nm} / 280 \mathrm{~nm}$. Following quantification of the RNA samples, cDNA was synthesized from 50-100 mg of total lung RNA using a Takara RNA PCR kit (AMV) Ver.3.0 (Takara, Bio, Inc.) and subjected to a semi-quantitative PCR using rTaq (Takara Bio, Inc.), according to the manufacturer's instructions. Briefly, the first-strand cDNA was synthesized in a $10 \mu \mathrm{l}$ reaction mixture containing total RNA, AMV Reverse Transcriptase, RNase Inhibitor, dNTP Mixture, $\mathrm{MgCl}_{2}, 10 \mathrm{X}$ RT buffer, and Random 9-mer as the reverse primer. The reverse-transcription reactions were carried out at $30^{\circ} \mathrm{C}$ for $10 \mathrm{~min}, 50^{\circ} \mathrm{C}$ for $30 \mathrm{~min}$, and $95^{\circ} \mathrm{C}$ for $2 \mathrm{~min}$, prior to being chilled to $5^{\circ} \mathrm{C}$ for $5 \mathrm{~min}$. The PCR cycle conditions were as follows: $94^{\circ} \mathrm{C}$ for $5 \mathrm{~min}$, followed by 28 cycles of $94^{\circ} \mathrm{C}$ for $30 \mathrm{sec}, 56^{\circ} \mathrm{C}$ for $30 \mathrm{sec}$ and $72^{\circ} \mathrm{C}$ for $60 \mathrm{sec}$, with a final extension step of $7 \mathrm{~min}$ at $72^{\circ} \mathrm{C}$ in a thermal cycler (Applied Biosystems Life Technologies, Foster City, CA, USA). The PCR products were electrophoresed on agarose gel (Takara, Bio, Inc.), stained with ethidium bromide (Sigma-Aldrich) and then visualized in a UV transilluminator (GAS7001B; UVItec Limited, Cambridge, UK), with images captured. GAPDH was used as an internal control. The primer sequences used in the present study were as follows: Forward: 5'-ATCTTCAAGCCGTCCTGTGT-3' and reverse: 5'-TGTTCTATCTTTCTTTGGTCTGC-3', for VEGF. Primers were obtained from Takara Bio, Inc., Dalian, China). The total lung RNA (50-100 mg) was reverse-transcribed and amplified using RT-qPCR as described.

Statistical analysis. The data are presented as the mean \pm standard deviation (SD). Following a test of homogeneity of variance, a one-way analysis of variance was used for multiple group comparisons. Pairwise multiple comparisons were performed using Dunnett's or the least significant difference test. A Kruskal-Wallis rank test was used for multiple comparisons of groups with unequal variances, and Dunn's method was used for pairwise multiple comparisons. All analyses were performed using SPSS version 13.0 (SPSS Inc., Chicago, IL, USA). P<0.05 was considered to indicate a statistically significant difference.

\section{Results}

Condition of the rats. All 24 rats in the four groups survived the 16 week treatment period. The mean \pm SD body weights in the $\mathrm{CtL}, \mathrm{Sm}, \mathrm{St}$ and SmSt groups following 16 weeks of treatment were $390.81 \pm 76.75,371.50 \pm 62.89,366.67 \pm 75.69$ and 
A

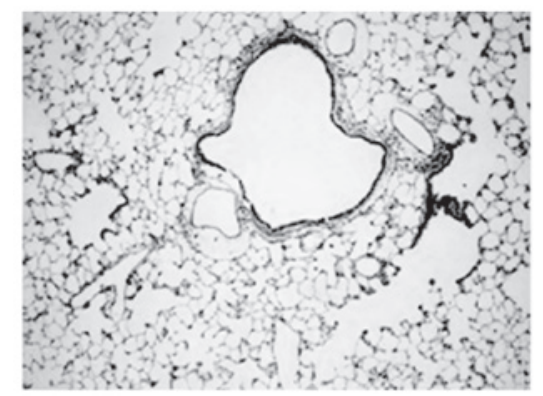

B

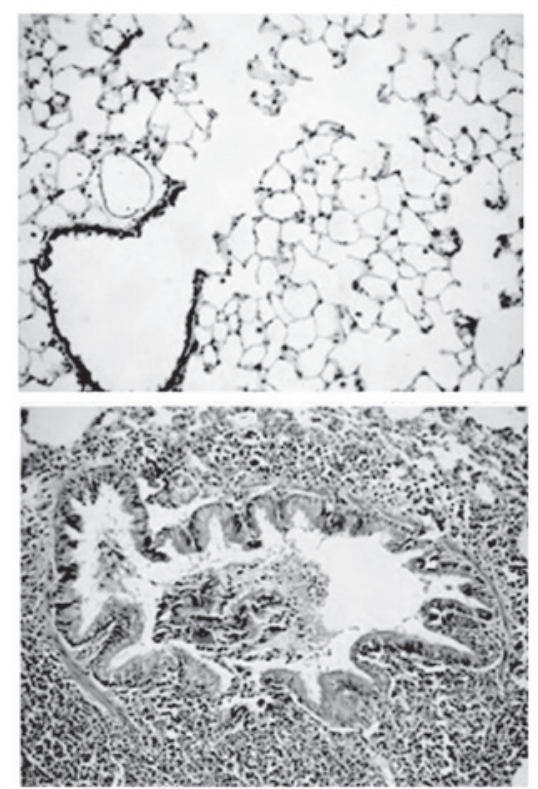

D

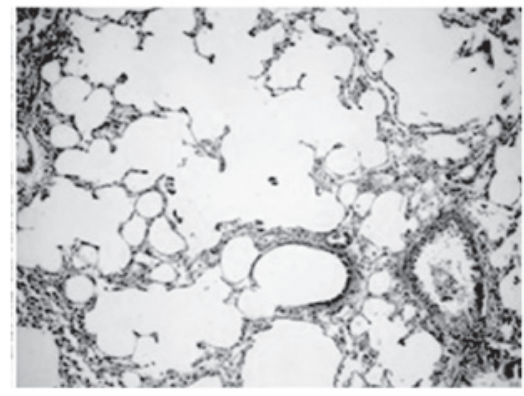

Figure 1. Lung histology using hematoxylin and eosin staining following 16 weeks of treatment in the four groups of rats. (A) Respiratory bronchioles, alveolar ducts and alveoli of healthy mice in the control group (low magnification). (B) Respiratory bronchioles, alveolar ducts and alveoli of healthy mice in the simvastatin-only group. (C) In the smoke exposure-only group, the bronchial and peribronchial tissue exhibited marked inflammatory cell infiltration. (D) In the smoke exposure \pm simvastatin treated group, inflammatory cell infiltration into the bronchial tissue was lower compared to other groups. Magnification, x400.

$322.83 \pm 66.03 \mathrm{~g}$, respectively. Although the body weights in the $\mathrm{Sm}, \mathrm{St}$ and $\mathrm{SmSt}$ groups were lower than those in the $\mathrm{CtL}$ group, the differences were not significant.

Reduction of small-airway inflammation and inhibition of cigarette smoke-induced emphysema by simvastatin. The histological changes in inflammatory cell infiltration, goblet cell hyperplasia/hypertrophy and airway smooth-muscle cell proliferation were significantly reduced in the SmSt group compared with those in the Sm group (Table I). The histological scoring revealed that simvastatin treatment led to lower TIS in the SmSt group compared with the Sm group $(\mathrm{P}<0.05)$.
No significant differences were observed between the TIS values in the SmSt and CtL groups (Table I; Fig. 1A-D)

Evaluation of the destruction of the alveolar architecture demonstrated that chronic exposure to cigarette smoke for 16 weeks caused higher lung parenchymal destruction in the $\mathrm{Sm}$ group compared with the $\mathrm{CtL}$ group, leading to the enlargement of air space. By contrast, simvastatin significantly inhibited lung destruction in the SmSt group. Following 16 weeks of treatment, the MLI levels in the Sm group were $35 \%$ higher than in the CtL group, and the MAN levels in the $\mathrm{Sm}$ group were $60 \%$ higher than in the CtL group. No significant differences were observed in MLI and MAN between the St and the control groups, however, in the SmSt group, MLI was significantly lower and MAN was significantly higher compared with the Sm group, the levels of MLI and MAN in the SmSt group were similar to those in the CtL group (Table I; Fig. 2A and B).

Simvastatin increases the smoke-induced reduction in VEGF. The mean concentrations of VEGF in the BALF and in the lung tissue samples were significantly lower in the Sm group, compared with those in the $\mathrm{CtL}$ group $(\mathrm{P}<0.01)$. In the SmSt group, simvastatin treatment led to significantly higher concentrations of VEGF in the BALF samples $(\mathrm{P}<0.01)$ and homogenate samples $(\mathrm{P}<0.01)$, compared with those in the $\mathrm{Sm}$ group (Table II).

Immunohistochemical VEGF staining and RT-PCR. The mRNA expression of $V_{E G F}$ was was lower in the lung tissue samples from the Sm group than in the CtL group. However, no significant differences were observed between the SmSt and CtL groups (Fig. 3). The expression of VEGF occurred predominantly in the SAECs $(51.3 \pm 2.9 \%)$ and AECs $(68.3 \pm 3.3 \%)$ of the $\mathrm{CtL}$ group, but was also present to a lesser extent, in the VECs $(8.5 \pm 0.8 \%)$ of the $\mathrm{CtL}$ group. Following 16 weeks of smoke exposure, the expression of VEGF was significantly lower in the $\mathrm{Sm}$ group compared with the $\mathrm{CtL}$ group in the SAECs $(16.3 \pm 2.7$ vs. $51.3 \pm 2.9 \%$, respectively; $\mathrm{P}<0.01)$ and in the AECs (27.0 \pm 5.9 vs. $68.3 \pm 3.2 \%$, respectively; $\mathrm{P}<0.01)$, however, simvastatin alone did not affect the expression of VEGF. The expression of VEGF was significantly higher in the SmSt group compared with the Sm group in the SAECs $(49.0 \pm 2.9$ vs. $16.3 \pm 2.7 \%$, respectively; $\mathrm{P}<0.01)$ and the AECs $(67.7 \pm 4.9$ vs. $27.0 \pm 5.9 \%$, respectively; $\mathrm{P}<0.01)$. However, no significant differences were observed in the expression of VEGF in the VECs between the SmSt and Sm groups $(6.3 \pm .6$ vs. $4.5 \pm 1.5 \%$, respectively; $\mathrm{P}>0.05)$. These findings are shown in Fig. 4A-C.

Increase of PCNA-positive AECs by simvastatin. The percentage of PCNA-positive AECs was significantly higher in the SmSt group compared with the Sm group $(10.3 \pm 1.9$ vs. $4.8 \pm 0.8 \%$, respectively; $\mathrm{P}<0.01)$ and $\mathrm{CtL}$ group $(7.0 \pm 1.7 \%, \mathrm{P}<0.01)$. However, the expression of PCNA was lower in the SAECs and VECs (Fig. 5A-C; Table III).

\section{Discussion}

The present study examined whether treatment with simvastatin attenuates cigarette smoke-induced emphysema in rats 
Table II. Levels of VEGF in lung homogenates and BALF.

\begin{tabular}{lcc}
\hline Group & BALF $(\mathrm{pg} / \mathrm{ml})$ & Homogenate $(\mathrm{ng} / \mathrm{ml})$ \\
\hline CtL & $199.85 \pm 20.46$ & $7.56 \pm 0.33$ \\
Sm & $71.49 \pm 16.22^{\mathrm{a}}$ & $4.15 \pm 0.11^{\mathrm{a}}$ \\
$\mathrm{St}$ & $201.30 \pm 17.61^{\mathrm{b}}$ & $6.86 \pm 0.16^{\mathrm{b}}$ \\
SmSt & $187.14 \pm 15.18^{\mathrm{b}}$ & $6.78 \pm 0.05^{\mathrm{b}}$ \\
F-statistic & 81.253 & 368.44 \\
P-value & $<0.01$ & $<0.01$
\end{tabular}

Values are presented as mean \pm standard deviation $(\mathrm{n}=6$ in each group). ${ }^{\text {a }}<0.01$, compared with the control group. ${ }^{\mathrm{b}} \mathrm{P}<0.01$, compared with the Sm group. VEGF, vascular endothelial growth factor; BALF, bronchoalveolar lavage fluid; $\mathrm{CtL}$, control; Sm, smoke exposed; st, simvastatin treated; SmSt, smoke exposed \pm simvastatin treated.

Table III. Positive expression of PCNA in rat lung tissue cells.

\begin{tabular}{lccc}
\hline Group & AECs & SAECs & VECs \\
\hline $\mathrm{CtL}$ & $7.00 \pm 1.67$ & $3.17 \pm 0.75$ & $0.00 \pm 0.00$ \\
$\mathrm{Sm}$ & $4.83 \pm 0.75^{\mathrm{a}}$ & $2.67 \pm 0.82$ & $0.00 \pm 0.00$ \\
$\mathrm{St}$ & $9.67 \pm 1.86^{\mathrm{b}}$ & $4.50 \pm 2.17$ & $0.17 \pm 0.41$ \\
SmSt & $10.33 \pm 1.97^{\mathrm{b}}$ & $4.50 \pm 2.51$ & $0.00 \pm 0.00$ \\
F-statistic & 14.387 & 1.721 & 1.000 \\
P-value & $<0.01$ & $<0.195$ & $<0.413$ \\
\hline
\end{tabular}

Values are presented as the mean \pm standard deviation $(n=6$ in each group). ${ }^{\text {a }}<0.01$, compared with the control group. ${ }^{\text {b }} \mathrm{P}<0.01$, compared with the Sm group. AECs, alveolar epithelial cells; SAEC, smallairway epithelial cells; VECs, vascular endothelial cells; PCNA, proliferating cell nuclear antigen; CtL, control; $\mathrm{Sm}$, smoke exposed; St, simvastatin treated; SmSt, smoke exposed + simvastatin treated.

by analyzing the expression of VEGF and lung morphology. Observations and epidemiological studies have demonstrated that statins may be beneficial for the treatment of COPD $(3,5,25)$. Different pathological abnormalities, including emphysema and chronic bronchitis, coexist in a number of patients with COPD, and emphysema, loss of elastic recoil and intrinsic airway abnormalities synergistically contribute to disease severity. There is evidence that significant small-airway pathology not only exists in patients with a chronically and radiographically documented emphysematous phenotype of COPD, but it also affects the outcome (26). Cigarette smoke causes primary lymphocyte infiltration into the small-airways, whereas simvastatin inhibits inflammatory infiltration around the bronchial branches. Animal model systems represent useful methods to assess the impact of cigarette smoke in patients with COPD (27). Emphysema is an anatomical lesion, which has been the focus of the majority of animal models $(27,28)$. Therefore, the present study selected a rat model to investigate the therapeutic effects of simvastatin on lung emphysema. The production of alveolar ducts was observed in lung samples from the model of smoke-induced emphysema; this change is anatomically similar to a mild form
A

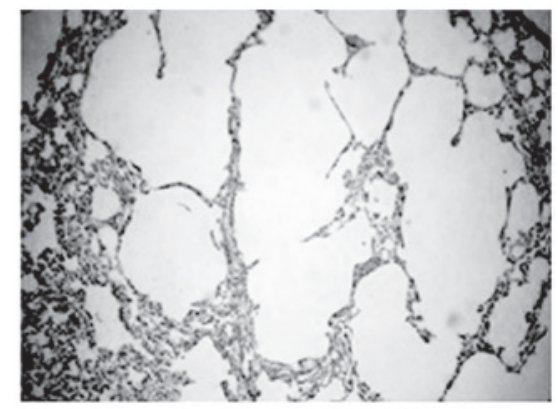

B

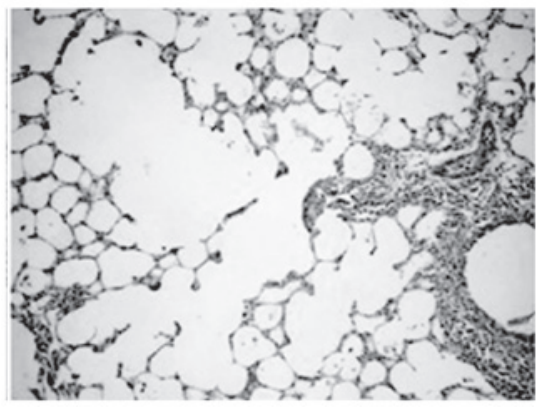

Figure 2. Hematoxylin and eosin staining. (A) In the smoke exposure-only group, alveolar ducts and alveoli were dilated and a number of alveolar septa were ruptured. (B) In the smoke exposure \pm simvastatin group, a number of alveoli were dilated. Magnification, x400.

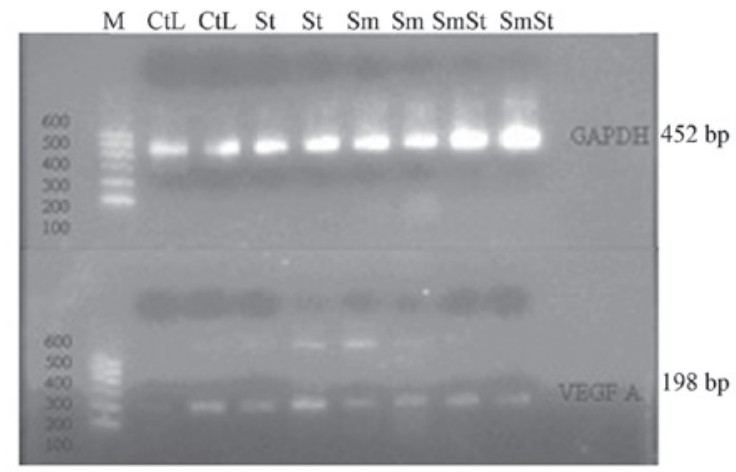

Figure 3. mRNA expression of VEGF in lung tissue samples from the four groups of rats. mRNA expression of VEGF198 was lower in the Sm group than in the CtL group. The mRNA expression of VEGF198 in the SmSt group was equivalent to that in the CtL group. M, molecular marker; VEGF, vascular endothelial growth factor; Sm, smoke exposed; St, simvastatin treated; SmSt, smoke exposed \pm simvastatin treated; CtL, control.

of centrilobular emphysema, commonly observed in cigarette smokers. The parenchyma between the dilated alveolar ducts is typically abnormal, with increases in the size and number of pores of Kohn, which connect adjacent alveoli (28), and is also observed in the lungs of human cigarette smokers. The lesions produced in laboratory animals can be subtle and, therefore, morphometric analysis, including MLI and MAN measurements is required to assess the degree of damage.

Small-airway remodeling, including increased matrix components, inflammatory-cell and goblet-cell metaplasia in the airways, with luminal narrowing, mucus-associated distortion and obstruction, is an important cause of airflow obstruction in human smokers (4). The results of the present study demonstrated that, following 16 weeks of cigarette smoke exposure, airway pathological scores were higher in 

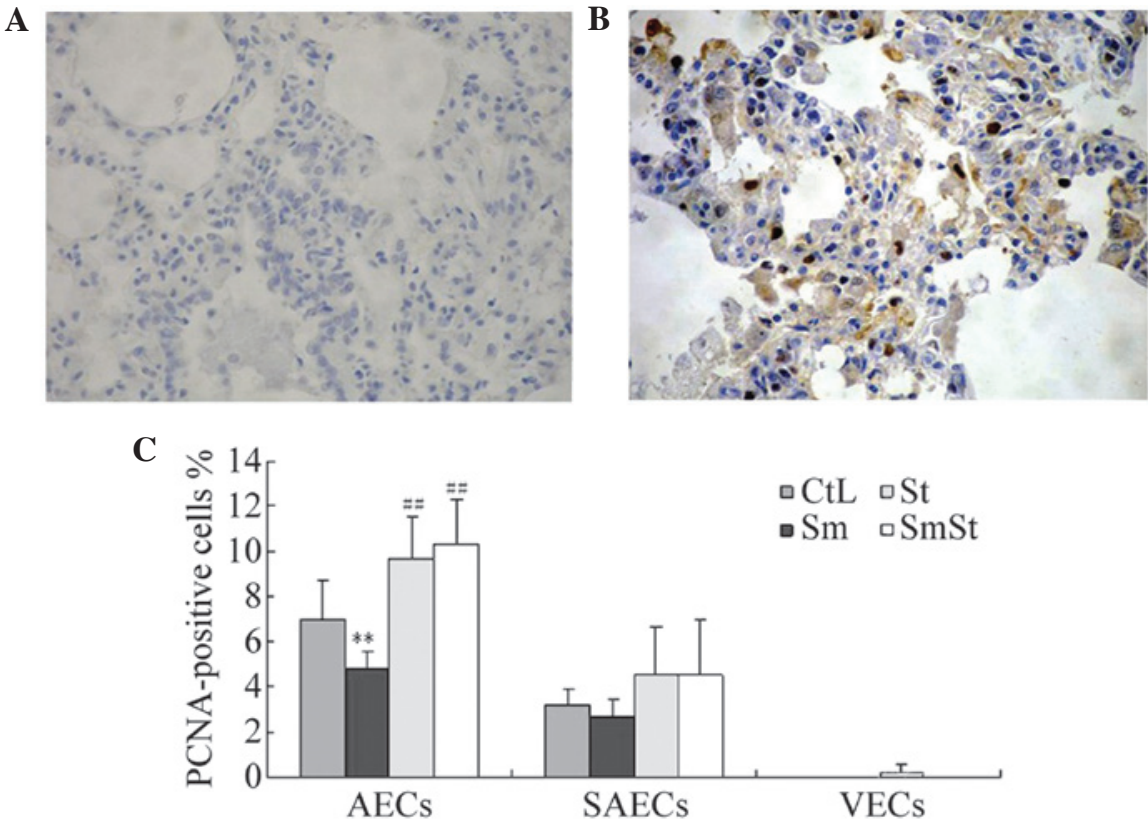

Figure 4. Immunohistochemical staining for VEGF. (A) Weak positive staining for VEGF was observed in the alveolar epithelial cells of the Sm group. (B) Marked positive staining for VEGF was observed in the alveolar epithelial cells of the SmSt group. (C) Immunohistochemical staining for VEGF in the lung cells from the four groups of rats. The percentages of VEGF-positive SAEC, AEC and VEC in the Sm group were significantly lower than those in the CtL group $\left({ }^{* *} \mathrm{P}<0.01\right)$. The expression levels of VEGF in the SAEC and AEC in the SmSt group were similar to those in the W group. There were significant difference sin the expression of VEGF between the SmSt and Sm groups in the AEC and SAEC ( $\left.{ }^{\# \# ~} \mathrm{P}<0.01\right)$, but not the VEC. VEGF, vascular endothelial growth factor; Sm. smoke exposed; St, simvastatin treated; SmSt, smoke exposed \pm simvastatin treated; SAEC, small airway epithelial cells; VEC, vascular endothelial cells; AEC, alveolar epithelial cells; CtL, control; PCNA, proliferating cell nuclear antigen.

A

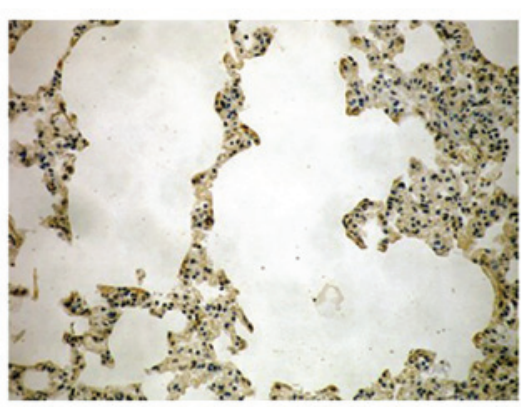

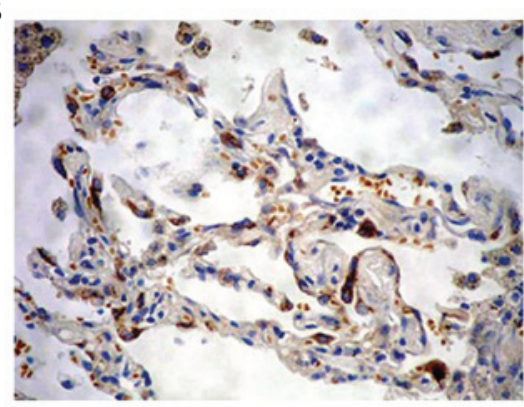

C

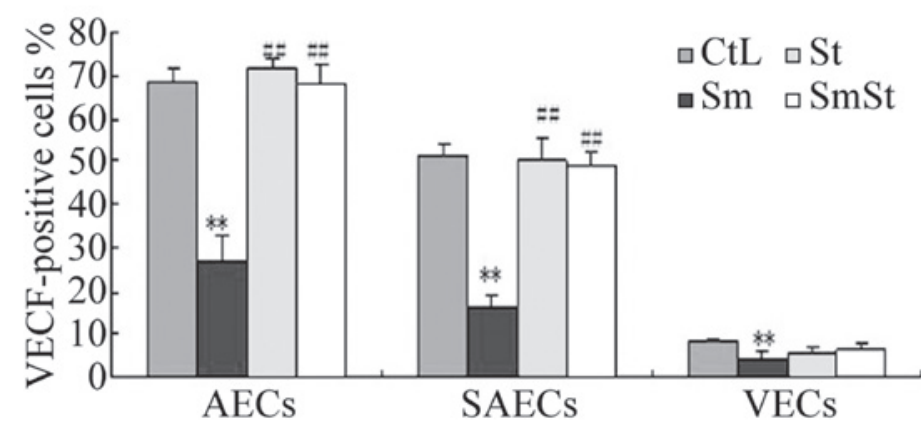

Figure 5. Immunohistochemical staining for PCNA, counter-stained using hematoxylin. Positively stained (brown) proliferating alveolar epithelial cells in (A) the CtL group and (B) the SmSt group. Original magnification, x400. (C) Immunohistochemical staining for PCNA in lung cells from the four groups of rats. The percentages of PCNA-positive AECs in the SmSt and St groups were significantly higher than those in the Sm group (\#\# $\mathrm{P}<0.01$ ). Lower expression levels of PCNA were observed in the SAECs and VECs compared with the AECs. CtL, control; PCNA, proliferating cell nuclear antigen; Sm. smoke exposed; Sm, simvastatin treated; SmSt, smoke exposed \pm simvastatin treated; SAEC, small airway epithelial cells; VEC, vascular endothelial cells.

the Sm group compared with those in the CtL group. These results suggested that the COPD rat model was a successful, appropriate experimental approach to for subsequent investigation. The results of the present study also demonstrated that simvastatin attenuated cigarette smoke-induced inflammatory infiltration, goblet-cell metaplasia and 
smooth-muscle proliferation disorders in the airway walls. The results of the present study are in accordance with those of other studies. Murphy et al (29) reported the effects of simvastatin on primary bronchial epithelial cells (PBECs) derived from stable lung allografts, which demonstrated the ability of simvastatin to attenuate airway neutrophilia, remodel mediators and inhibit their upregulation in response to transforming growth factor and interleukin-17. This finding and those of other studies have demonstrated the potential of simvastatin in alleviating neutrophilic airway inflammation and causing lung remodeling (30-32).

Previous studies have identified the presence of VEGF and its receptors in several cell types of a number of organs. It has been reported that the expression levels of VEGF levels in the lungs is the highest among normal tissues (33). The observations that increased expression of VEGF or VEGF signaling causes experimental emphysema and that the lungs of patients with COPD have decreased expression levels of VEGF and VEGF receptor-2 (VEGFR) have led to the suggestion that alveolar maintenance is required for structural preservation of the lungs (34). In the present study, the expression levels of VEGF in lung tissues and BALF samples from the Sm group were lower than in the $\mathrm{W}$ group. Simvastatin treatment of rats exposed to cigarette smoke significantly increased the levels of VEGF, almost to the same level as the CtL group (control group). The mRNA expression levels of VEGF were similar in the lung tissues and BALF samples. In the SmSt group, simvastatin increased the expression of VEGF in the AECs compared with the Sm group. These results suggested that simvastatin treatment may prevent the cigarette smoke-induced decrease of VEGF in lung tissue and may upregulate the expression of VEGF in the AECs.

Statins are involved in improving endothelial cell function and promoting angiogenesis. They increase the production of vasodilators, including nitric oxide and VEGF, and decrease the production of vasoconstrictors, including endothelin-1, triggering oxidative stress (35). Takahashi et al (25) demonstrated that the concentration gradient of VEGF between the lungs and the circulatory system increases in response to simvastatin treatment in an emphysema model. BALF consists of an airway epithelial-cell lining fluid (ELF), which was diluted with saline in each rat. The concentration of VEGF in the ELF is suggested to be higher than in the plasma, since the measured BALF concentrations were similar to those in the plasma.

Asahara et al (36) and Brown et al (37) demonstrated that VEGF induces the mobilization of endothelial progenitor cells, and stimulation of resident AECs. In the present study, treatment with $5 \mathrm{mg} / \mathrm{kg}$ day $^{-1}$ simvastatin induced epithelial cell proliferation. Therefore, VEGF may directly and indirectly promote tissue-specific proliferation of AECs.

The present study had several limitations. Firstly, only the direct morphological impact of simvastatin on rats was measure, and was not a mechanistic investigation. Another limitation was the use of a dose of $5 \mathrm{mg} / \mathrm{kg}$ simvastatin and 16 week time-period only. Therefore, it was not possible to investigate whether there were dose- or time-dependent effects of simvastatin. In addition, no physiological data regarding lung function were assessed and no in vitro data were available. Statins may exert pleiotropic effects in COPD via multiple pathways, and the pathogenesis of COPD is complicated. It would, therefore, be beneficial to investigate the mechanisms underlying statin involvement with COPD, in order to understand their clinical relevance and applicability.

In conclusion, the results of the present study demonstrated that simvastatin exhibits a significant impact on the expression of VEGF and attenuates cigarette smoke-induced emphysema in rats. It was hypothesized that simvastatin, at least in part, may exert beneficial effects in patients with COPD. Further investigation into the mechanisms of statins is required in order to improve the pathophysiology and to alleviate the symptoms of COPD.

\section{Acknowledgements}

This study was supported by the National Scientific Foundation of China (grant no. 2007BAI24804).

\section{References}

1. World Health Statistics: 2008. Geneva: World Health Organization. Available from URL: http:/www.who.int/whosis/ whostat/2008/en/index.html.

2. Zhong N, Wang C, Yao W, Chen P, Kang J, Huang S, Chen B, Wang C, Ni D, Zhou Y, et al: Prevalence of chronic obstructive pulmonary disease in China: A large, population-based survey. Am J Respir Crit Care Med 176: 753-760, 2007.

3. Hogg JC, Chu F, Utokaparch S, Woods R, Elliott WM, Buzatu L, Cherniack RM, Rogers RM, Sciurba FC, Coxson $\mathrm{HO}$ and Paré PD: The nature of small-airway obstruction in chronic obstructive pulmonary disease. N Engl J Med 350: 2645-2653, 2004.

4. Hogg JC: Pathophysiology of airflow limitation in chronic obstructive pulmonary disease. Lancet 364: 709-721, 2004.

5. Mead J, Turner JM, Macklem PT and Little JB: Significance of the relationship between lung recoil and maximum expiratory flow. J Appl Physiol 229: 95-108, 1967.

6. Liebow AA: Pulmonary emphysema with special reference to vascular changes. Am Rev Respir Dis 80: 67-93, 1959.

7. Kasahara Y, Tuder RM, Taraseviciene-Stewart L, Le Cras TD, Abman S, Hirth PK, Waltenberger J and Voelkel NF: Inhibition of VEGF receptors causes lung cell apoptosis and emphysema. J Clin Invest 106: 1311-1319, 2000.

8. Suzuki M, Betsuyaku T, Nagai K, Fuke S, Nasuhara Y, Kaga K, Kondo S, Hamamura I, Hata J, Takahashi H and Nishimura M: Decreased airway expression of vascular endothelial growth factor in cigarette smoke-induced emphysema in mice and COPD patients. Inhal Toxicol 20: 349-359, 2008.

9. Young RP, Hopkins R and Eaton TE: Pharmacological actions of statins: Potential utility in COPD. Eur Respir Rev 18: 222-232, 2009.

10. Janda S, Park K, FitzGerald JM, Etminan M and Swiston J: Statins in COPD: A systematic review. Chest 136: 734-743, 2009.

11. Liao JK and Laufs U: Pleiotropic effects of statins. Annu Rev Pharmacol Toxicol 45: 89-118, 2005.

12. Veillard NR, Braunersreuther V, Arnaud C, Burger F, Pelli G, Steffens S and Mach F: Simvastatin modulates chemokine and chemokine receptor expression by geranylgeranyl isoprenoid pathway in human endothelial cells and macrophages. Atherosclerosis 188: 51-58, 2006.

13. Wolfrum S, Jensen KS and Liao JK: Endothelium-dependent effects of statins. Arterioscler Thromb Vasc Biol 23: 729-736, 2003.

14. Frick M, Dulak J, Cisowski J, Józkowicz A, Zwick R, Alber H, Dichtl W, Schwarzacher SP, Pachinger O and Weidinger F: Statins differentially regulate vascular endothelial growth factor synthesis in endothelial and vascular smooth muscle cells. Atherosclerosis 170: 229-236, 2003.

15. Taraseviciene-Stewart L, Scerbavicius R, Choe KH, Cool C, Wood K, Tuder RM, Burns N, Kasper M and Voelkel NF: Simvastatin causes endothelial cell apoptosis and attenuates severe pulmonary hypertension. Am J Physiol Lung Cell Mol Physiol 291: L668-L676, 2006. 
16. Cho SJ, Kim JS, Kim JM, Lee JY, Jung HC and Song IS: Simvastatin induces apoptosis in human colon cancer cells and in tumor xenografts, and attenuates colitis-associated colon cancer in mice. Int J Cancer 123: 951-957, 2008.

17. Punturieri A, Szabo E, Croxton TL, Shapiro SD and Dubinett SM: Lung cancer and chronic obstructive pulmonary disease:needs and opportunities for integrated research. J Natl Cancer Inst 101: 554-559, 2009.

18. Ueda K, Jinbo M, Li TS, Yagi T, Suga K and Hamano K: Computed tomography-diagnosed emphysema, not airway obstruction, is associated with the prognostic outcome of early-stage lung cancer. Clin Cancer Res 12: 6730-6736, 2006

19. Xu J, Liu X, Chen J, Zacharek A, Cui X, Savant-Bhonsale S, Liu Z and Chopp M: Simvastatin enhances bone marrow stromal cell differentiation into endothelial cells via notch signaling pathway. Am J Physiol Cell Physiol 296: C535-C543, 2009.

20. Architectural and technical code for laboratory animal facility (GB50447-2008). National Standard of the People's Republic of China. China Architecture \& Building Press, Beijing, China. 2008.

21. Lee JH, Lee DS, Kim EK, Choe KH, Oh YM, Shim TS, Kim SE, Lee YS and Lee SD: Simvastatin inhibits cigarette smoking-induced emphysema and pulmonary hypertension in rat lungs. Am J Respir Crit Care Med 172: 987-993, 2005.

22. Zhang HY, Pang BS, Niu SJ, Ma L, Xin P and Weng XZ: Expression of matrix metalproteinases in lung tissue and levels of some cytokines in bronchoalveolar lavage fluid in the obstructive emphysema rat models. Chin J Inter Med 42: 181-185, 2003.

23. Vernooy HJ, Dentener MA, van Suylen RJ, Buurman WA and Wouters EF: Long-term intratracheal lipopolysaccharide exposure in mice results in chronic lung inflammation and persisient pathology. Am J Respir Cell Mol Biol 26:152-159, 2002.

24. Kasagi S, Seyama K, Mori H, Souma S, Sato T, Akiyoshi T, Suganuma $\mathrm{H}$ and Fukuchi Y: Tomato juice prevents senescence-accelerated mouse P1 strain from developing emphysema induced by chronic exposure to tobacco smoke. Am J Physiol Lung Cell Mol Physiol 290: L396-L404, 2006.

25. Takahashi S, Nakamura H, Seki M, Shiraishi Y, Yamamoto M, Furuuchi M, et al: Reversal of elastase -induced pulmonary emphysema and promotion of alveolar epithelial cell proliferation by simvastatin in mice. Am J Physiol Lung Cell Mol Physiol 294: L882-L890, 2008

26. Patel BJ, Marchetti N, Kim V, Gaughan JP and Criner GJ: Airway wall thickness correlates with dynamic hyperinflation in severe COPD. Proc Am Thorac Soc (abstract) 3: A712, 2006.
27. Wright JL, Cosio M and Churg A: Animal models of chronic obstructive pulmonary disease. Am J Physiol Lung Cell Mol Physiol 295: L1-L15, 2008.

28. Wright JL: The importance of ultramicroscopic emphysema in cigarette smoke-induced lung disease. Lung 179: 71-81, 2001.

29. Murphy DM, Forrest IA, Corris PA, Johnson GE, Small T, Jones D, Fisher AJ, Egan JJ, Cawston TE, Ward C and Lordan JL: Simvastatin attenuates release of neutrophilic and remodeling factors from primary bronchial epithelial cells derived from stable lung transplant recipients. Am J Physiol Lung Cell Mol Physiol 294: L592-L599, 2008.

30. Ou XM, Wen FQ, Uhal BD, Feng YL, Huang XY, Wang T, Wang K, Liu DS, Wang X and Chen L: Simvastatin attenuates experimental small airway remodelling in rats. Respirology 14 : 734-745, 2009.

31. Davis BB, Zeki AA, Bratt JM, Wang L, Filosto S, Walby WF, Kenyon NJ, Goldkorn T, Schelegle ES and Pinkerton KE: Simvastatin inhibits smoke-induced airway epithelial injury: Implications for COPD therapy. Eur Respir J 42: 350-361, 2013.

32. Takeda N, Kondo M, Ito S, Ito Y, Shimokata K and Kume H: Role of RhoA inactivation in reduced cell proliferation of human airway smooth muscle by simvastatin. Am J Respir Cell Mol Biol 35: 722-729, 2006.

33. Kaner RJ, Ladetto JV, Singh R, Fukuda N, Matthay MA and Crystal RG: Lung overexpression of the vascular endothelial growth factor gene induces pulmonary edema. Am J Respir Cell Mol Biol 22: 657-664, 2000.

34. Marwick JA, Stevenson CS, GiddingsJ, MacNee W, Butler K, Rahman I and Kirkham PA: Cigarette smoke disrupts VEGF165-VEGFR-2 receptor signaling complex in rat lungs and patients with COPD: Morphological impact of VEGFR-2 inhibition. Am J Physiol Lung Cell Mol Physiol 290: L897-L908, 2006.

35. Bayorh MA, Ganafa AA, Eatman D, Walton M and Feuerstein GZ: Simvastatin and losartan enhance nitric oxide and reduce oxidative stress in salt-induced hypertension. Am J Hypertens 18: 1496-1502, 2005.

36. Asahara T, Takahashi T, Masuda H, Kalka C, Chen D, Iwaguro H, Inai Y, Silver M and Isner JM: VEGF contributes to postnatal neovascularization by mobilizing bone marrow-derived endothelial progenitor cells. EMBO J 18: 3964-3972, 1999.

37. Brown KR, England KM, Goss KL, Snyder JM and Acarregui MJ: VEGF induces airway epithelial cell proliferation in human fetal lung in vitro. Am J Physiol Lung CellMol Physiol 281: L1001-L1010, 2001. 